\title{
Nutritional and Chemical Composition and Antiviral Activity of Cultivated Seaweed Sargassum naozhouense Tseng et Lu
}

\author{
Yan Peng ${ }^{1}$, Enyi Xie ${ }^{2}$, Kai Zheng ${ }^{3}$, Mangaladoss Fredimoses ${ }^{1}$, Xianwen Yang ${ }^{1}$, Xuefeng Zhou ${ }^{1}$, \\ Yifei Wang ${ }^{3}$, Bin Yang ${ }^{1}$, Xiuping Lin ${ }^{1}$, Juan Liu ${ }^{1}$ and Yonghong Liu ${ }^{1, *}$
}

1 Key Laboratory of Marine Bio-resources Sustainable Utilization, Guangdong Key Laboratory of Marine Materia Medica, RNAM Center for Marine Microbiology, South China Sea Institute of Oceanology, Chinese Academy of Sciences, Guangzhou 510301, China;

E-Mails: py00_2006@126.com (Y.P.); moses10c@gmail.com (M.F.); xwyang@scsio.ac.cn (X.Y.); xfzhou@scsio.ac.cn (X.Z.); binggo525@163.com (B.Y.); xiupinglin@hotmail.com (X.L.); ljuan2010@qq.com (J.L.)

2 Fisheries College, Guangdong Ocean University, Zhanjiang 524025, China;

E-Mail: xieenyi@163.com

3 Guangzhou Jinan Biomedicine Research and Development Center, Jinan University, Guangzhou 510632, China; E-Mails: twangyf@jnu.edu.cn (K.Z.); twangyf@jnu.edu.cn (Y.W.)

* Author to whom correspondence should be addressed; E-Mail: yonghongliu@scsio.ac.cn; Tel./Fax: +86-20-8902-3244.

Received: 29 October 2012; in revised form: 29 November 2012 / Accepted: 5 December 2012 / Published: 27 December 2012

\begin{abstract}
Sargassum naozhouense is a brown seaweed used in folk medicine and applied for thousands of years in Zhanjiang, Guangdong province, China. This study is the first time to investigate its chemical composition and antiviral activity. On the dry weight basis, this seaweed was constituted of $c a .35 .18 \%$ ash, $11.20 \%$ protein, $1.06 \%$ lipid and $47.73 \%$ total carbohydrate, and the main carbohydrate was water-soluble polysaccharide. The protein analysis indicated the presence of essential amino acids, which accounted for $36.35 \%$ of the protein. The most abundant fatty acids were C14:0, C16:0, C18:1 and $\mathrm{C} 20: 4$. The ash fraction analysis indicated that essential minerals and trace elements, such as $\mathrm{Fe}, \mathrm{Zn}$ and $\mathrm{Cu}$, were present in the seaweed. IR analysis revealed that polysaccharides from cultivated $S$. naozhouense may be alginates and fucoidan. The polysaccharides possessed strong antiviral activity against $\mathrm{HSV}-1$ in vitro with $\mathrm{EC}_{50}$ of $8.92 \mu \mathrm{g} / \mathrm{mL}$. These results demonstrated cultivated $S$. naozhouense has a potential for its use in functional foods and antiviral new drugs.
\end{abstract}


Keywords: Sargassum naozhouense; seaweed; chemical composition; antiviral activity

\section{Introduction}

Seaweeds, classified into red algae (Rhodophyta), brown algae (Ochrophyta, Phaeophyceae) and green algae (Chlorophyta) [1,2], are a renewable natural resource with extensive distribution along the Pacific coast [3]. They have been used mainly for human consumption (e.g., as food or as crude drugs to treat gallstone, stomach ailment, eczema, cancer, renal disorders, scabies, psoriasis, asthma, arteriosclerosis, heart disease, lung diseases and ulcers) and extraction of hydrocolloids, such as agar, carrageens and alginates, but are still under-exploited [3-10]. In recent years, seaweeds have caused emerging interest in biomedicine and the food area, because they possess a wealth of bioactive compounds (such as sulfated polysaccharides, carotenoids, dietary fiber, protein, essential fatty acids, vitamins, minerals, terpenoids, oxylipins, phlorotannins and steroids) with potential industrial and agricultural applications [11-16]. For example, alginates from brown algae are often used as additives to ameliorate the texture of food [7]. Therefore, seaweeds are a promising renewable resource with considerable commercial potential for further exploitation.

Brown seaweeds (e.g., Sargassum fusiforme and Saccharina japonica-formerly Laminaria japonica) have been used as Traditional Chinese Medicines in China for thousands of years [17,18]. Sargassum naozhouense Tseng et $\mathrm{Lu}$, an edible brown algae widely distributed along the coasts of Zhanjiang, Guangdong province, China, is commonly consumed as a sea vegetable or as crude drugs for treating internal heat, infections, laryngitis and other ailments in locals [19]. According to literature reports, the wild S. naozhouense is rich in polysaccharides, amino acids and trace elements [19]. However, little is known about the cultivated $S$. naozhouense, especially its nutritional and functional properties. For full utilization of this rich resource, it is imperative to evaluate the nutritional and functional properties of the cultivated S. naozhouense. In general, the nutritional properties are usually estimated by the chemical composition. Moreover water-soluble sulfated polysaccharides are the main constituents of seaweed cell walls, with potent antiviral activities, particularly against HSV [20,21]. Therefore, the aim of this study was to investigate the chemical composition of cultivated S. naozhouense and the anti-HSV activity of water-soluble polysaccharide from cultivated S. naozhouense.

\section{Results and Discussion}

\subsection{Chemical Composition of Cultivated S. naozhouense}

The ash, protein and total carbohydrate were the most abundant constituents in S. naozhouense (Table 1). The average contents of protein and ash were $11.20 \%$ and $35.18 \%$ in dry weight, respectively, which were close to those reported for the wild S. naozhouense (13.95\% and 41.79\%) [19] and higher than those of Saccharina japonica $(8.70 \%$ and $20.00 \%)$ [22]. Furthermore, the protein content was comparable to that recorded for some species of the same genus, i.e., S. henslowianum (11.52\%) and S. fusiforme (15.38\%) [23,24]. 
Table 1. Chemical composition of cultivated S. naozhouense (\%, w/w on the dry basis) ${ }^{\mathrm{a}}$.

\begin{tabular}{cc}
\hline Components & Values \\
\hline Ash & 35.18 \\
Protein & 11.20 \\
Lipid & 1.06 \\
Total carbohydrate & 47.73 \\
Total water-soluble carbohydrate & 29.74 \\
Water-soluble polysaccharide & 21.01 \\
Total dietary fiber & 4.83 \\
\hline
\end{tabular}

${ }^{\mathrm{a}}$ Average of four analyses.

Interestingly, the total carbohydrate level (47.73\%) was higher than that reported for S. fusiforme (46.01\%) and wild S. naozhouense (29.37\%) [19,24]. Moreover, the main carbohydrates were water-soluble polysaccharides $(21.01 \%)$, yet the dietary fiber content $(4.83 \%)$ was relatively lower. On the other hand, the lipid content $(1.06 \%)$ was relatively lower. This result was similar to that of wild S. naozhouense (2.4\%) and other edible brown algae, such as Saccharina japonica (0.2\%) and S. fusiforme $(0.69 \%)[22,24]$.

\subsection{Amino Acid Composition}

The amino acid composition of proteins in cultivated S. naozhouense was illustrated (Table 2). The contents of amino acids ranged from 0.54 to $13.21 \mathrm{~g} / 100 \mathrm{~g}$ protein. The proteins of cultivated S. naozhouense contained a high level of amino acids, especially essential amino acids (EEA), e.g., leucine (6.52 g/100 g protein) and valine (4.64 g/100 g protein). Furthermore, all essential amino acids, such as valine, methionine, isoleucine, leucine, phenylalanine, lysine, histidine, arginine and tryptophan, accounting for $47.22 \%$ of the total amino acids, were present in this seaweed. The ratio value of EAA/NEAA and the essential amino acid index (EAAI) were 0.89 and 66.24, respectively. According to FAO/WHO recommended standards of ideal protein [25], the protein of cultivated $S$. naozhouense belongs to a high-quality protein. Furthermore, the protein quality is better than that of S. fusiforme, because cysteine is lacking in S. fusiforme [24].

In addition, the aspartic (8.39 g/100 g protein) and glutamic acids (13.21 g/100 g protein), non-essential amino acids (NEEA), were the most abundant amino acids and accounted for $28 \%$ of total amino acids, which, together with glycine $(4.38 \mathrm{~g} / 100 \mathrm{~g}$ protein) and alanine $(5.27 \mathrm{~g} / 100 \mathrm{~g}$ protein), were responsible for the special flavor and taste of cultivated S. naozhouense. 
Table 2. Amino acid composition of cultivated $S$. naozhouense (g/100 g protein) ${ }^{\mathrm{a}}$.

\begin{tabular}{cccc}
\hline Amino acids & Contents & Amino acids & Contents \\
\hline Aspartic acid & 8.39 & Tyrosine & 2.95 \\
Threonine & 3.93 & Phenylalanine & 4.38 \\
Serine & 3.21 & Histidine & 1.07 \\
Glutamic acid & 13.21 & Lysine & 3.66 \\
Proline & 3.30 & Arginine & 4.20 \\
Glycine & 4.38 & Tryptophan & 0.89 \\
Alanine & 5.27 & Total & 76.97 \\
Valine & 4.64 & EAA & 36.35 \\
Methionine & 2.41 & NEAA & 40.62 \\
Cysteine & 0.54 & EAA/NEAA & 0.89 \\
Isoleucine & 4.02 & EAAI & 66.24 \\
Leucine & 6.52 & & \\
\hline
\end{tabular}

a Average of four analyses; EAA: essential amino acids, Threonine, Valine, Methionine, Isoleucine, Leucine, Phenylalanine, Lysine, Histidine, Arginine, and Tryptophan; NEAA: non-essential amino acids; EAAI: essential amino acid index.

\subsection{Fatty Acid Composition}

The fatty acid composition of cultivated $S$. naozhouense is presented (Table 3). This seaweed contained high concentrations of saturated fatty acids (SAFA, 33.63\% of total of fatty acid), monounsaturated fatty acid (MUFA, $10.42 \%$ of total of fatty acid), and polyunsaturated fatty acid (PUFA, 18.84\% of total of fatty acid), even though it had a low level of lipid.

The main fatty acids in cultivated $S$. naozhouense were C14:0 (myristic acid), C16:0 (palmitic acid), C18:1 (oleic acid) and C20:4 (arachidonic acid), which were also the most abundant fatty acids in edible seaweed S. fusiforme [24]. However, C16:0 (palmitic acid), C18:0 (stearic acid) and C18:1 (oleic acid) were the most abundant fatty acids in wild S. naozhouense [19].

Table 3. Fatty acid composition of cultivated S. naozhouense (\% of total of fatty acid) ${ }^{\mathrm{a}}$.

\begin{tabular}{|c|c|c|c|}
\hline Fatty acids & Methyl esters (\%) & Fatty acids & Methyl esters (\%) \\
\hline C6:0 & 0.44 & $\mathrm{C} 18: 3 \omega 3$ & 0.25 \\
\hline C8:0 & 0.49 & C20:1 & 0.53 \\
\hline $\mathrm{C} 12: 0$ & 0.34 & $\mathrm{C} 20: 3 \omega 6$ & 2.95 \\
\hline $\mathrm{C} 14: 0$ & 6.7 & $\mathrm{C} 20: 4 \omega 6$ & 9.61 \\
\hline $\mathrm{C} 15: 0$ & 0.3 & $\mathrm{C} 20: 5 \omega 3$ & 1.38 \\
\hline C16:0 & 24.61 & $\mathrm{C} 22: 0$ & 0.21 \\
\hline C16:1 & 3.55 & SAFA & 33.63 \\
\hline $\mathrm{C} 16: 2 \omega 6$ & 0.22 & MUFA & 10.42 \\
\hline C18:0 & 0.54 & PUFA & 18.84 \\
\hline C18:1 & 6.34 & PUFA $\omega 6$ & 13.24 \\
\hline C18:2trans & 3.97 & PUFA $\omega 3$ & 1.63 \\
\hline 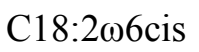 & 0.46 & Ratio $\omega 6 / \omega 3$ & 8.12 \\
\hline
\end{tabular}

a Average of four analyses; SAFA: saturated fatty acids; MUFA: monounsaturated fatty acids; PUFA: polyunsaturated fatty acids. 
Although our study revealed that cultivated $S$. naozhouense had higher total levels of PUFA than MUFA, the eicosapentaenoic acid (EPA, C20:5

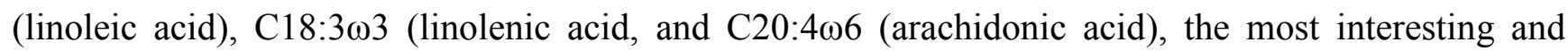
important fatty acids in terms of nutrition, were present in this seaweed. Further, the ratio of $\omega 6 / \omega 3$, which the WHO currently recommends should not be higher than 10 in diet as a whole [26], was 8.12, which indicated the cultivated $S$. naozhouense may be used as a sea vegetable or an ingredient to reduce $\omega 6 / \omega 3$ ratio in diet.

\subsection{Mineral Contents}

Different mineral elements (such as potassium, sodium, phosphorus, calcium, iron, zinc, manganese, copper and cadmium) were analyzed by inductive coupled plasma-optical emission spectroscopy (ICP-OES) and were summarized (Table 4). The cultivated S. naozhouense contained significant amounts of essential minerals (e.g., potassium, sodium, calcium and phosphorus), like S. fusiforme and wild S. naozhouense [19,24]. Potassium (4170 mg/100 g dry weight) was the most abundant element in the seaweed, followed by sodium $(3250 \mathrm{mg} / 100 \mathrm{~g})$, phosphorus $(120 \mathrm{mg} / 100 \mathrm{~g})$ and calcium $(66.98 \mathrm{mg} / 100 \mathrm{~g})$. The ratio of $\mathrm{Na} / \mathrm{K}(0.77)$ was relatively lower, which was interesting from the point of view of nutrition, because high $\mathrm{Na} / \mathrm{K}$ ratio diets and the incidence of hypertension are closely connected [27]. Consequently, the cultivated S. naozhouense may be useful for the regulation of the $\mathrm{Na} / \mathrm{K}$ ratio of diets.

On the other hand, cultivated S. naozhouense also contained trace elements, such as iron, manganese, zinc, copper and cadmium. Iron was the most abundant trace element (147 mg/100 g), followed by $\mathrm{Zn}(9.08 \mathrm{mg} / 100 \mathrm{~g})$. The content levels of other trace elements (Table 4) were similar to those recorded in the earliest reports on seaweeds [15,28]. Furthermore, the contents of some heavy metal elements ( $\mathrm{As}, \mathrm{Cd}, \mathrm{Cu}, \mathrm{Hg}$ and $\mathrm{Pb}$ ) in this seaweed were below the toxic limits allowed in some countries [29]. Hence, cultivated $S$. naozhouense may be used as a food supplement to provide the daily intake of some trace elements (e.g., iron, zinc) for adults, especially iron, since iron deficiency would lead to anemia, when the demand for iron is high in growth, high menstrual loss and pregnancy [27].

Table 4. Mineral composition of cultivated S. naozhouense (mg/100 g) a .

\begin{tabular}{cc}
\hline Minerals & Contents \\
\hline $\mathrm{K}$ & 4170 \\
$\mathrm{Na}$ & 3250 \\
$\mathrm{P}$ & 120 \\
$\mathrm{Ca}$ & 66.98 \\
$\mathrm{Fe}$ & 147 \\
$\mathrm{Zn}$ & 9.08 \\
$\mathrm{Mn}$ & 5.84 \\
$\mathrm{Cu}$ & 0.36 \\
$\mathrm{Cd}$ & 0.17 \\
\hline
\end{tabular}

${ }^{\mathrm{a}}$ Average of four analyses. 


\subsection{Properties of Polysaccharide}

The content of water-soluble polysaccharides from cultivated S. naozhouense was $21.01 \%$ (Table 1). The IR spectrum of polysaccharides was recorded in a potassium bromide pellet using an IR spectrophotometer. In the IR spectrum (Figure 1), it is being observed that a broad peak at $3415 \mathrm{~cm}^{-1}$ and a small peak at $2930 \mathrm{~cm}^{-1}$ are due to the stretching vibrations of $\mathrm{O}-\mathrm{H}$ and $\mathrm{C}-\mathrm{H}$, respectively. The bands at 1613 and $1415 \mathrm{~cm}^{-1}$ were attributed to carboxylate $\mathrm{O}-\mathrm{C}-\mathrm{O}$ asymmetric stretching and to $\mathrm{C}-\mathrm{OH}$ deformation vibrations, respectively. The absorption at $1039 \mathrm{~cm}^{-1}$ was assigned to $\mathrm{C}-\mathrm{O}$ and $\mathrm{C}-\mathrm{C}$ stretching vibrations of the pyranose ring. The anomeric region of the fingerprint $\left(950-750 \mathrm{~cm}^{-1}\right)$ exhibited three characteristic absorption bands in alginate polysaccharides (Figure 1, bands at 896, 821 and $777 \mathrm{~cm}^{-1}$, respectively). The band at $896 \mathrm{~cm}^{-1}$ is assigned to the $\beta$-anomeric $\mathrm{C}-\mathrm{H}$ deformation vibration of $\beta$-mannuronic acid residues. The band at $821 \mathrm{~cm}^{-1}$ seems to be characteristic of mannuronic acid residues. The band at $777 \mathrm{~cm}^{-1}$ is assigned to gluluronic acid [30]. In addition, a broad band at $1249 \mathrm{~cm}^{-1}$ indicated the presence of sulphated ester groups $(\mathrm{S}=\mathrm{O})$, which is a characteristic component in fucoidan [31-33]. Therefore, the water-soluble polysaccharides from cultivated $S$. naozhouense may be alginates and fucoidan, which should be further demonstrated by more studies in the future.

Figure 1. FT-IR spectrum of water-soluble polysaccharides from cultivated S. naozhouense.

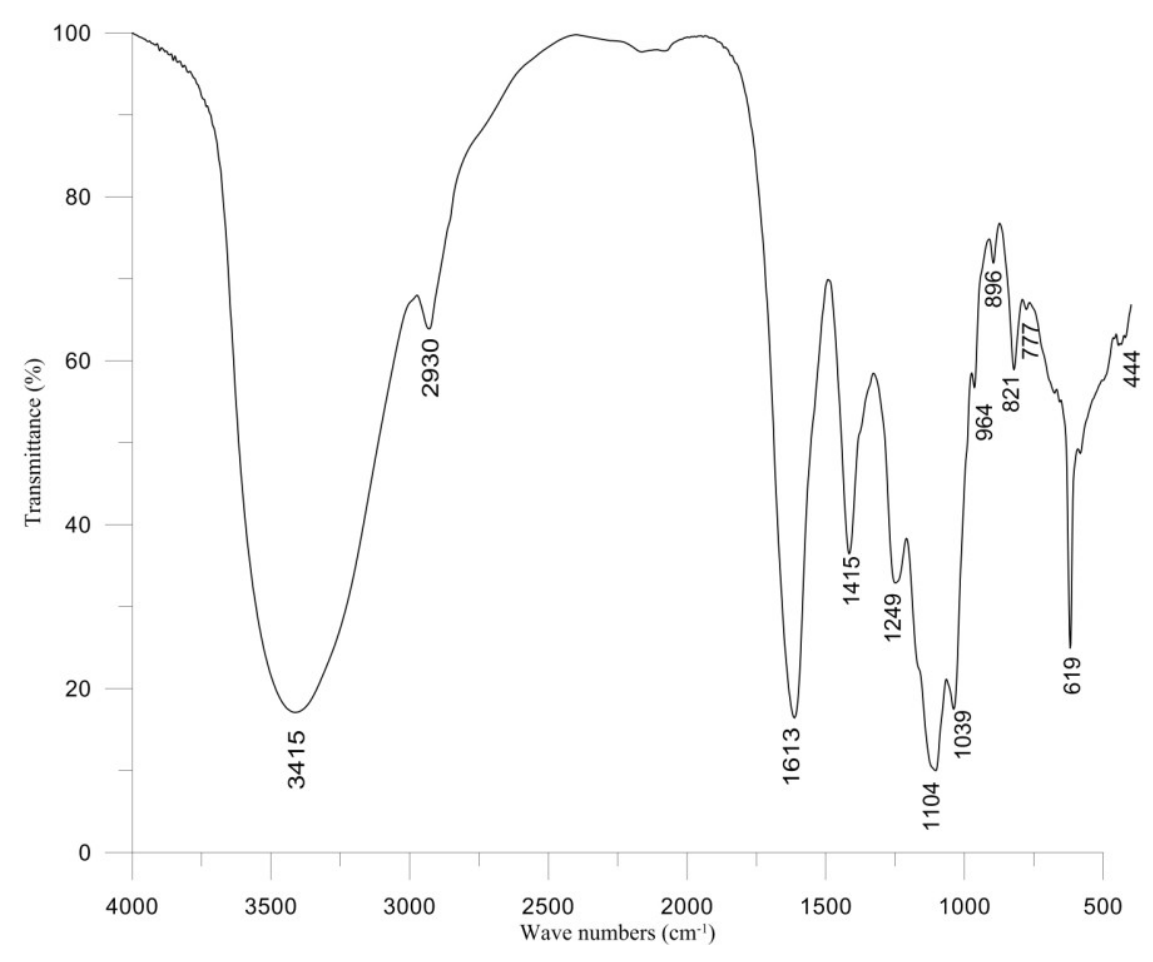

\subsection{Cytotoxic and Antiviral Activities of the Polysaccharides}

The polysaccharides exhibited lower cytotoxicity on Vero cells $\left(\mathrm{CC}_{50}, \mathrm{MCC}>200 \mu \mathrm{g} / \mathrm{mL}\right)$. After Vero cells had been treated by various polysaccharide dilutions for two days, cell morphology did not have any visible alteration under a phase-contrast microscope, and cell layer also did not have any destruction by MTT reduction assay. 
The polysaccharide showed strong antiviral activity against $\mathrm{HSV}-1$ strain $\mathrm{F}$ at $\geq 12.5 \mu \mathrm{g} / \mathrm{mL}$ $\left(\mathrm{EC}_{50}=8.92 \mu \mathrm{g} / \mathrm{mL}\right)$. In order to compare antiviral potential of the polysaccharides, acyclovir (ACV) was used as a positive control and conferred more than $75 \%$ cellular protection at $20 \mu \mathrm{g} / \mathrm{mL}$, which was in agreement with that the polysaccharides at $12.5 \mu \mathrm{g} / \mathrm{mL}$ (Table 5). Moreover, the selectivity index (SI, $\mathrm{CC}_{50} / \mathrm{EC}_{50}$ ), which was often higher than 10 for a sample with antiviral activity [7], was more than 22. It is clear that water-soluble polysaccharides from cultivated $S$. naozhouense possess anti-HSV-1 activity in vitro.

Herpes simplex virus type 1 (HSV-1), a common human pathogen, is responsible for a broad range of human infectious diseases. Though ACV is served as a drug to successfully treat the HSV infections, ACV-resistant strains have been found in immune-compromised patients and drug toxicity has also been reported [34,35]. Therefore, searching for new antiviral agents is urgently needed. Natural bioactive compounds are the best resources for the development of new anti-HSV drugs due to their greater efficiency with less toxicity. Sulfated polysaccharides from marine algae, including sulfated mannans, galactans, agarans, fucoidans, sulfated rhamnogalactans, fucans and different types of carrageenans, were showed to be active against some enveloped viruses, especially HSV and HIV [21,36-39]. In this study, the sulfated water-soluble polysaccharides showed strong antiviral activity against $\mathrm{HSV}-1$ strain $\mathrm{F}$ in vitro within noncytotoxic concentration. Consequently, the sulfated polysaccharides from marine algae are a good resource for searching novel therapeutic candidates for HSV.

Table 5. Effect on HSV-1strain F replication in Vero cells and cytotoxicity of polysaccharide from cultivated $S$. naozhouense.

\begin{tabular}{|c|c|c|c|c|c|c|c|c|c|c|}
\hline \multirow{5}{*}{ Polysaccharide } & $\begin{array}{c}\text { Concentration } \\
(\mu \mathrm{g} / \mathrm{mL})\end{array}$ & 100 & 50 & 25 & 12.5 & 6.25 & 3.12 & 1.56 & 0.78 & $\begin{array}{c}\text { Virus } \\
\text { contrast }\end{array}$ \\
\hline & $\mathrm{CPE}$ & - & - & - & + & ++++ & ++++ & ++++ & ++++ & ++++ \\
\hline & $\mathrm{EC}_{50}(\mu \mathrm{g} / \mathrm{mL})$ & \multicolumn{9}{|c|}{8.92} \\
\hline & $\mathrm{CC}_{50}(\mu \mathrm{g} / \mathrm{mL})$ & \multicolumn{9}{|c|}{$>200$} \\
\hline & $\operatorname{MCC}(\mu \mathrm{g} / \mathrm{mL})$ & \multicolumn{9}{|c|}{$>200$} \\
\hline \multirow{3}{*}{ Acyclovir (ACV) } & Concentration & \multirow{2}{*}{\multicolumn{9}{|c|}{20}} \\
\hline & $(\mu \mathrm{g} / \mathrm{mL})$ & & & & & & & & & \\
\hline & $\mathrm{CPE}$ & \multicolumn{9}{|c|}{+} \\
\hline
\end{tabular}

\section{Experimental Section}

\subsection{Algal Material}

The cultivated S. naozhouense was collected from Techeng Island, Guangdong province of China in July 2011 and identified by Professor Weixin Li and Dr. Xie Enyi, Fisheries College, Guangdong Ocean University, China. A voucher specimen (No. P110701) was deposited in the Key Laboratory of Marine Bio-resources Sustainable Utilization, South China Sea Institute of Oceanology, Chinese Academy of Sciences, Guangzhou, China. The fresh seaweeds were washed in freshwater to remove sediment, epifauna and epiphytes, and then dried in the air for $10 \mathrm{~h}$, powdered and stored in plastic bags at $4{ }^{\circ} \mathrm{C}$ until further experiment use. 


\subsection{Chemical Composition}

Total nitrogen was quantified by the Kjeldahl method, and then, the protein content was estimated by multiplying the total nitrogen content by a nitrogen conversion factor of 6.25 [8]. Total ashes were determined by incinerating seaweed samples in a digitally controlled furnace with temperature being gradually increased to $550{ }^{\circ} \mathrm{C}$ and maintaining for $6 \mathrm{~h}$, and then were quantified gravimetrically [40]. Total lipids, total water-soluble carbohydrates and total dietary fibers were determined by the Soxhlet method, anthrone-sulfuric acid colorimetry and the gravimetric method, respectively [40]. Total carbohydrate was determined by the difference method [24]. Polysaccharide content was estimated by the phenol-sulfuric acid method, using glucose as a standard substance [41]. Amino acids were determined by high-performance liquid chromatography (HPLC) according to the GB/T 5009.124-2003 standard method [42]. Fatty acid composition was determined by gas chromatography-mass spectrometry (GC-MS) analysis of their methyl esters on a Varian Gas Chromatograph series 3800 fitted with a VF-5 MS fused silica capillary column (30 $\mathrm{m} \times 0.25 \mathrm{~mm}$, film thickness $0.25 \mu \mathrm{m}$, USA) [43]. Mineral analysis was made by inductive coupled plasma-optical emission spectroscopy (ICP-OES) [43].

\subsection{Preparation of Polysaccharides}

Approximate $20.0 \mathrm{~g}$ seaweed powder were accurately weighed and defatted in a Soxhlet apparatus with petroleum ether $\left(60-90{ }^{\circ} \mathrm{C}\right)$, then pretreated twice with $80 \%$ ethanol to remove some pigments, monosaccharides, oligosaccharides and other small molecule materials. After the organic solvent was volatilized, the pretreated seaweed powder was extracted twice with distilled water at $90{ }^{\circ} \mathrm{C}$ for $1.5 \mathrm{~h}$ and filtered. The combined aqueous extracts were concentrated in a rotary evaporator to a certain volume under reduced pressure at $50{ }^{\circ} \mathrm{C}$, followed by treatment with Sevag Reagent to remove protein and centrifugation at $5000 \mathrm{rpm}$ for $20 \mathrm{~min}$ to obtain the supernatant. Then the supernatant was poured into six volumes of $100 \%$ ethanol and was kept at $4{ }^{\circ} \mathrm{C}$ overnight. The precipitate containing crude polysaccharides was collected by centrifugation, then washed with $70 \%$ ethanol, $100 \%$ ethanol, ethyl ether and acetone, respectively, and finally, freeze-dried, weighed and kept in a vacuum dryer [44-46].

\subsection{FT-IR Spectroscopy}

Infrared spectra were recorded from a $\mathrm{KBr}$ pellet of the polysaccharide on a spectrometer FT-IR Nicolet 6700.

\subsection{Determination of Antiviral Activity of the Sulfated Polysaccharide}

\subsubsection{Cells and Virus}

African green monkey kidney cells (Vero, ATCC CCL-81), provided by Wuhan Institute of Virology, Chinese Academy of Sciences, were cultured in Dulbecco's modified Eagle medium (DMED, Invitrogen) supplemented with 10\% FBS (Invitrogen), 0.22\% sodium bicarbonate (Sigma) and $50 \mathrm{mg} / \mathrm{L}$ gentamycin (Invitrogen). HSV-1 strain F (ATCC VR733), obtained from Hong Kong University, was propagated in Vero cells and stored at $-80{ }^{\circ} \mathrm{C}$ until use. 


\subsubsection{Cytotoxicity Assay}

Cytotoxicity of the polysaccharides on Vero cells was evaluated in vitro by MTT assay as described by Mosmann [47]. Vero cells $\left(1 \times 10^{4}\right.$ cells/well) were seeded in 96 -well plates and incubated at $37{ }^{\circ} \mathrm{C}$ in $5 \% \mathrm{CO}_{2}$ atmosphere for $24 \mathrm{~h}$. Then, various dilutions (concentration from 3.12 to $200 \mu \mathrm{g} / \mathrm{mL}$ ) of polysaccharide were added to wells, with quadruplicate wells for each concentration, and further incubated for $48 \mathrm{~h}$; meanwhile, cells were examined daily under a phase-contrast microscope to determine the minimum concentration of polysaccharide (MCC) that caused a microscopically detectable alteration of cell morphology. Afterwards, MTT solution was added (final concentration $0.5 \mathrm{mg} / \mathrm{mL}$ ) to each well. After $4 \mathrm{~h}$ of incubation at $37^{\circ} \mathrm{C}$, the supernatant was removed, and the dimethyl sulfoxide (DMSO) was added to solubilize the formazan crystals, then the optical density (OD) was measured in a microplate reader at $570 \mathrm{~nm}$. The cytotoxicity was expressed as $50 \%$ cytotoxic concentration $\left(\mathrm{CC}_{50}\right)$, which was the concentration of the test substances required to reduce cell growth by $50 \%$.

\subsubsection{Antiviral Activity Assay}

The antiviral activity of the polysaccharide was evaluated by cytopathic effect (CPE) inhibition assay [48]. In general, Vero cells were seeded in 96-well plates at a density of $1 \times 10^{4}$ cells per well and allowed to form a monolayer. The confluent cell monolayer was treated with serial two-fold dilutions of polysaccharide and an equal volume of virus suspension $\left(100 \mathrm{TCID}_{50}\right)$ in quadruplicate in 96-well plates and then incubated at $37^{\circ} \mathrm{C}$ in a 5\% $\mathrm{CO}_{2}$ atmosphere and observed daily for $\mathrm{CPE}$ under a light microscope. Meanwhile, acyclovir (ACV) was served as a positive control. The $50 \%$ effective antiviral concentration $\left(\mathrm{EC}_{50}\right)$, defined as the concentration that reduced $\mathrm{CPE}$ by $50 \%$ with respect to the virus control, was calculated by MTT method.

\section{Conclusions}

The edible cultivated brown algae $S$. naozhouense was investigated for its potential nutritional value and antiviral activity for the first time. It is characterized by a high level of proteins and a low level of lipid, like S. fusiforme and Saccharina japonica used in human nutrition [18] and, therefore, can be used for human consumption as an alternative source of essential amino acids and some polyunsaturated acids, such as oleic, linoleic, linolenic and eicosapentaenoic acids, or as functional ingredients to reduce calories and modify the texture of formulated foods. This seaweed is also rich in some minerals, such as iron and zinc, and so may be used as a food supplement to supply these minerals at low inclusion levels. Especially, the protein in cultivated $S$. naozhouense was better than that in S. fusifome, because cystein was present in the former. In this regard, cultivated S. naozhouense has higher nutritional value compared to $S$. fusiforme, which has been consumed as a longevity sea vegetable in Chinese traditional diets and may be a better alternative resource of the Traditional Chinese Medicine S. fusifome.

On the other hand, cultivated $S$. naozhouense has a high level of water-soluble polysaccharides, which is very interesting, because pharmacological and biological activities of polysaccharides from marine algae in therapeutic applications for humans are already well-known [49]. Furthermore, the 
water-soluble polysaccharides contained sulfate groups and exhibited strong antiviral activity against $\mathrm{HSV}-1$ strain $\mathrm{F}$ in vitro with an $\mathrm{EC}_{50}$ of $8.92 \mu \mathrm{g} / \mathrm{mL}$ and a SI of $>22$. Hence, the polysaccharide from cultivated $S$. naozhouense has a potential in antiviral new drugs. Further studies should be carried out for the isolation, characterization and other biological screening of the polysaccharide.

In summary, the brown alga $S$. naozhouense may represent an interesting advance in the search for novel functional applications in relevant industrial uses, including pharmaceuticals, nutraceuticals, cosmeceuticals and functional foods.

\section{Acknowledgments}

This study was supported by the National Basic Research Program of China (973 Program, Nos. 2010CB833800 and 2011CB915503), the National High Technology Research and Development Program (863 Program, 2012AA092104) and the National Natural Science Foundation of China (Nos. 30973679, 21172230, 31270402, and 21002110), Guangdong Province-CAS Joint Research Program (2011B090300023).

\section{References}

1. Gupta, S.; Abu-Ghannam, N. Bioactive potential and possible health effects of edible brown seaweeds. Trends Food Sci. Technol. 2011, 22, 315-326.

2. Pereira, L. A Review of the Nutrient Composition of Selected Edible Seaweeds Ecology. In Seaweed: Nutrient Composition and Medicinal Uses; Pomin, V.H., Ed.; Nova Science Publishers Inc.: Now York, NY, USA, 2011; pp. 15-47.

3. Ortiz, J.; Romero, N.; Robert, P.; Araya, J.; Lopez-Hernández, J.; Bozzo, C.; Navarrete, E.; Osori, A.; Rios, A. Dietary fiber, amino acid, fatty acid and tocopherol contents of the edible seaweeds Ulva lactuca and Durvillaea antarctica. Food Chem. 2006, 99, 98-104.

4. Besada, V.; Andrade, J.M.; Schultze, F.; González, J.J. Heavy metals in edible seaweeds commercialized for human consumption. J. Mar. Syst. 2009, 75, 303-315.

5. Cruz-Suárez, L.E.; León, A.; Peña-Rodríguez, A.; Rodríguez-Peña, G.; Moll, B.; Ricque-Marie, D. Shrimp/Ulva co-culture: A sustainable alternative to diminish the need for artificial feed and improve shrimp quality. Aquaculture 2010, 301, 64-68.

6. Fleurence, J. Seaweed proteins: Biochemical, nutritional aspects and potential uses. Trends Food Sci. Technol. 1999, 10, 25-28.

7. Lee, J.B.; Takeshita, A.; Hayashi, K.; Hayashi, T. Structures and antiviral activities of polysaccharides from Sargassum trichophyllum. Carbohydr. Polym. 2011, 86, 995-999.

8. Denis, C.; Morancais, M.; Li, M.; Deniaud, E.; Gaudin, P.; Wielgosz-Collin, G.; Barnathan, G.; Jaouen, P.; Fleurence, J. Study of the chemical composition of edible red macroalgae Grateloupia turuturu from Brittany (France). Food Chem. 2010, 119, 913-917.

9. Holdt, S.L.; Kraan, S. Bioactive compounds in seaweed: Functional food applications and legislation. J. Appl. Phycol. 2011, 23, 543-597.

10. Cornish, M.L.; Garbary, D.J. Antioxidants from macroalgae: Potential applications in human health and nutrition. Algae 2010, 25, 155-171. 
11. Rupérez, P.; Saura-Calixto, F. Dietary fiber and physicochemical properties of edible Spanish seaweeds. Eur. Food Res. Technol. 2001, 212, 349-354.

12. Lahaye, M.; Kaeffer, B. Seaweed dietary fibres: Structure, physic-chemical and biological properties relevant to intestinal physiology. Sci. Aliment. 1997, 17, 619-639.

13. Yan, X.; Nagata, T.; Fan, X. Antioxidative activities in some common seaweeds. Plant Foods Hum. Nutr. 1998, 52, 253-262.

14. Bhaskar, N.; Miyashita, K. Lipid composition of Padina tetratomatica (Dictyotales, Pheophyta), a brown seaweed of the west coast of India. Indian J. Fish. 2005, 52, 263-268.

15. Mabeau, S.; Fleurence, J. Seaweed in food products: Biochemical and nutritional aspects. Trends Food Sci. Technol. 1993, 4, 103-107.

16. Zhang, C.Y.; Wu, W.H.; Wang, J.; Lan, M.B. Antioxidant properties of polysaccharide from the brown seaweed Sargassum graminifolium (Turn.), and its effects on calcium oxalate crystallization. Mar. Drugs 2012, 10, 119-130.

17. Wang, J.; Zhang, Q.; Zhang, Z.; Zhang, H.; Niu, X. Structural studies on a novel fucogalactan sulfated from the brown seaweed Laminaria japonica. Int. J. Biol. Macromol. 2010, 47, 126-131.

18. Editorial Committee of Chinese Materia Medica; State Administration of Traditional Chinese Medicine. Chinese Materia Medica; Shanghai Science and Technology Press: Shanghai, China, 1999; pp. 435-483.

19. Wang, B.; Huang, H.; Xiong, H.P.; Xie, E.Y.; Li, Z.M. Analysis on nutrition constituents of Sargassum naozhouense sp. nov. Food Res. Dev. 2010, 31, 195-197.

20. Zhu, W.; Ooi, V.E.C.; Ang, P.O.J.; Chan, P.K.S. Isolation and characterization of a sulfated polysaccharide from the brown alga Sargassum patens and determination of its anti-herpes activity. Biochem. Cell Biol. 2003, 81, 25-33.

21. Witvrouw, M.; de Clercq, E. Sulfated polysaccharides extracted from sea algae as potential antiviral drugs. Gen. Pharmacol. 1997, 29, 497-511.

22. Zhao, M.J. Nutrition evaluation of the edible seaweed. Fish. Sci. 1990, 28-31.

23. Chem, S.; Wang, W.; Liu, H.; Li, C. Chemical constituents in Sargassum henslowianum and its nutrition evaluation. Food Res. Dev. 2010, 31, 154-156.

24. Dai, Z.; Hong, Y.; Zhang, Y.; Zhang, H. Evaluation on nutritional components of Sargassum fusiforme. J. Fish. China 2002, 26, 382-384.

25. Li, B.F. Marine Food Nutrition and Health Characteristics. In Marine Health Food; Chemical Industry Press: Beijing, China, 2009; pp. 51-72.

26. Sánchez-Machado, D.I.; López-Cervantes, J.; López-Hernández, J.; Paseiro-Losada, P. Fatty acids, total lipid, protein and ash contents of processed edible seaweeds. Food Chem. 2004, 85, 439-444.

27. Li, D. Non-Energy Nutrients: Mineral. In Food Nutrition; Chemical Industry Press: Beijing, China, 2011; pp. 140-146.

28. Ortega-Calvo, J.J.; Mazuelos, C.; Hermosín, B.; Sáiz-Jiménez, C. Chemical composition of Spirulina and eukaryotica algae food products marked in Spain. J. Appl. Phycol. 1993, 5, 425-435. 
29. Indegaard, M.; Minsaas, J. Seaweed Resources in EUROPE: Uses and Potential. In Animal and Human Nutrition; Guiry, M.D., Blunden, G., Eds.; John Wiley \& Sons Ltd.: Chichester, UK, 1991; pp. 21-64.

30. Chandía, N.P.; Matsuhiro, B.; Vásquez, A.E. Alginic acids in Lessonia trabeculata: Characterization by formic acid hydrolysis and FT-IR spectroscopy. Carbohydr. Polym. 2001, 46, 81-87.

31. Asare, S.O. Seasonal changes in sulphate and 3,6-anhydrogalactose content of phycocolloids from two red algae. Bot. Mar. 1980, 23, 595-598.

32. Stancioff, D.J.; Stanley, N.F. Infrared and chemical studies on algal polysaccharides. Proc. Int. Seaweed Symp. 1969, 6, 595-609.

33. Chandía, N.P.; Matsuhiro, B. Characterization of a fucoidan from Lessonia vadosa (Phaeophyta) and its anticoagulant and elicitor properties. Int. J. Biol. Macromol. 2008, 42, 235-240.

34. Coen, D.M. Antiviral drug resistance in herpes simplex virus. Adv. Exp. Med. Biol. 1996, 394, 49-57.

35. Ernst, M.E.; Franey, R.J. Acyclovir- and ganciclovir-induced neutrotoxicity. Ann. Pharmacother. 1998, 32, 111-113.

36. Wijesekara, I.; Pangestuti, R.; Kim, S.K. Biological activities and potential health benefits of sulfated polysaccharides derived from marine algae. Carbohydr. Polym. 2011, 84, 14-21.

37. Chen, J.H.; Lim, J.D.; Sohn, E.H.; Choi, Y.S.; Han, E.T. Growth-inhibitory effect of a fucoidan from brown seaweed Undaria pinnatifida on plasmodium parasites. Parasitol. Res. 2009, 104, $245-250$.

38. Hemmingson, J.A.; Falshaw, R.; Furneaux, R.H.; Thompson, K. Structure and antiviral activity of the galactofucan sulfates extracted from Undaria pinnatifida (Phaeophyta). J. Appl. Phycol. 2006, $18,185-193$.

39. Queiroz, K.C.S.; Medeiros, V.P.; Queiroz, L.S.; Abreu, L.R.D.; Rocha, H.A.O.; Ferreira, C.V.; Jucá, M.B.; Aoyama, H.; Leite, E.L. Inhibition of reverse transcriptase activity of HIV by polysaccharides of brown algae. Biomed. Pharmacother. 2008, 62, 303-307.

40. Dalian Polytechnic University; South China University of Technology; Northwest University of Light Industry; Zhengzhou University of Light Industry; Hubei University of Technology; Qiqihar University of Light Industry; South China Agricultural University; Shengyang Agricultural University. Food Analysis; China Light Industry Press: Beijing, China, 2006; pp. 99-206.

41. Dubois, M.; Gilles, K.A.; Hamilton, J.K.; Rebers, P.A.; Smith, F. Colorimetric method for determination of sugar and related substance. Anal. Chem. 1956, 28, 350-356.

42. Chinese Center for Disease Control and Prevention. Determination of Amino Acids in Foods; Ministry of Health of the People's Republic of China: Beijing, China, 2003; pp. 117-119.

43. Association of Official Analytical Chemists. Official Methods of Analysis, 18th ed.; Association of Official Analytical Chemists: Washington, DC, USA, 2006; pp. 2-247.

44. Ye, H.; Wang, K.; Zhou, C.; Liu, J.; Zeng, X. Purification, antitumor and antioxidant activities in vitro of polysaccharides from the brown seaweed Sargassum pallidum. Food Chem. 2008, 111, $428-432$. 
45. Chen, Y.; Xie, M.; Zhang, H.; Wang, Y.; Nie, S.; Li, C. Quantification of total polysaccharides and triterpenoids in Ganoderma lucidum and Ganoderma atrum by near infrared spectroscopy and chemometrics. Food Chem. 2012, 135, 268-275.

46. Haslin, C.; Lahaye, M.; Pellegrini, M. Chemical composition and structure of sulphated water-soluble cell-wall polysaccharides from the gametic, carposporic and tetrasporic stages of Asparagopsis armata Harvey (Rhodophyta, Bonnemaisoniaceae). Bot. Mar. 2000, 43, 475-482.

47. Mosmann, T. Rapid colorimetric assay for cellular growth and survival: Application to proliferation and cytotoxicity assays. J. Immunol. Methods 1983, 65, 55-63.

48. Peng, Y.; Zheng, J.; Huang, R.; Wang, Y.; Xu, T.; Zhou, X.; Liu, Q.; Zeng, F.; Ju, H.; Yang, X.; et al. Polyhydroxy steroids and saponins from China Sea starfish Asterina pectinifera and their biological activities. Chem. Pharm. Bull. 2010, 58, 856-858.

49. Che, C.T. Marine products as a source of antiviral drugs leads. Drug Dev. Res. 1991, 23, 201-218.

Samples Availability: Available from the authors.

(C) 2012 by the authors; licensee MDPI, Basel, Switzerland. This article is an open access article distributed under the terms and conditions of the Creative Commons Attribution license (http://creativecommons.org/licenses/by/3.0/). 